\title{
BOTRYOSPHAERIA DOTHIDEA (MOUG.) AFECTANDO PLANTACIONES DE MANZANO Y DURAZNERO DE LA REGIÓN CENTRO - ESTE DE SANTA FE
}

\author{
RISTA, L. M. ${ }^{1} ;$ MAUMARY, R. ${ }^{1}$; Gariglio, N. F. ${ }^{1} \&$ FAVARO, J. C. ${ }^{1}$
}

\begin{abstract}
RESUMEN
Troncos, ramas y frutos de manzanos y durazneros cultivados en la zona centro-este de Santa Fe presentaron cancros que provocaban el secado del órgano afectado. Los objetivos del trabajo fueron identificar el/los organismos causales de la enfermedad y describir la sintomatologia observada en manzanos. En muestreos periódicos de tres fincas se colectaron ramas y frutos afectados, los cuales fueron lavados, desinfectados y acondicionados para la siembra e incubados. También se realizaron montajes microscópcos. En los aislamientos se desarrollaron colonias con picnidios conteniendo conidios de $22,6 \mu$ to $26 \mu \times 5$ a $6 \mu$. Los ascomas, tomados de la corteza infectada, fueron de color negro, con ascos claviformes y ascosporas elípticas o fusoidales, hialinas, de $28,6 \pm 2,1 \mu \times 13,3 \pm 1,7$ $\mu$. En varas sanas, inoculadas, selladas con parafina estéril, y llevadas a cámara húmeda, se observó un incremento de la superficie de la herida, mientras que los testigos permanecieron sin alteración. La prueba de patogenicidad y los reaislamientos confirmaron la identificación de Botryosphaeria dothidea (Moug.). La sintomatología en manzanos consistió en cancros amplios y profundos y de gran tamaño en ramas y troncos que secaban el órgano y la planta. En Argentina, se lo identificó en arándano y en vid, siendo este el primer reporte en duraznero y manzano.

Palabras claves: Botryosphaeria dothidea, manzano, duraznero.
\end{abstract}

1.- Grupo de trabajo de Cultivos Intensivos, Facultad de Ciencias Agrarias (UNL). Kreder 2805 Esperanza, provincia de Santa Fe. Email: Irista@fca.unl.edu.ar

Proyecto subsidiado por el Programa C.A.I. + D de la Universidad Nacional del Litoral Manuscrito recibido el 4 de abril de 2011 y aceptado para su publicación el 14 de junio de 2011 